\title{
EFFECT OF FLUCTUATION OF WETTING AND DRYING PHENOMENA ON SOIL FERTILITY STATUS UNDER RICE CULTIVATION IN WETLAND SOIL IN RWANDA
}

 \\ ${ }^{1}$ Lecturers at University of Rwanda, College of Agriculture, Animal sciences and Veterinary Medicine, Huye \\ Campus(UR-CAVM); \\ ${ }^{2}$ Senior lecturer at Institute polytechnique of Byumba( IPB) \\ Corresponding Author: nk.taremwa@ gmail.com
}

\begin{abstract}
Since 1980, wetland s in Rwanda have been considered as important areas for agriculture intensification through improving food security and incomes to the farmers. However, changes in the soil nutrient status due to repeatedly wetting and drying phenomena may considerably affect soil fertility status thus leading to low crop productivity of the wetlands. This has consequently created fear to the wetland users especially the local farmers, extension workers and agronomists. The comparative study was conducted to assess the effect of drained and irrigated phenomena at Mamba, Rwasave and Rugeramigozi marshlands on soil fertility change under rice growing. 24 samples were taken with 12 samples under drained and 12 under irrigated areas. The samples were collected randomly from top soil $\quad(0-20 \mathrm{~cm})$. The following parameters were quantified; soil $\mathrm{pH}\left(\mathrm{H}_{2} \mathrm{O}\right)$ in soil water suspension with ratio 1:2.5; $\mathrm{Al}$ exchangeable( $1 \mathrm{~N} \mathrm{Kcl}$ ), organic carbon( walkely and black method in Sumner method modified (1984), Total nitrogen kjeldahl (TNK) in Bremner modified method, available phosphorus ( bray 1). Bases exchangeable with $1 \mathrm{~N}$ ammonium acetate following AAS and CEC and available $\mathrm{Fe}, \mathrm{Zn}, \mathrm{Cu}$ and Mn (DTDA) diethylenetriaminepentaacetic acid. Data analyses were processed with GEN STAT version 3. The results showed that the fluctuation of wet and dry water have significantly affected soil fertility status at $\mathrm{p}=0,05$. The phosphorus and potassium are in the low levels of deficiency $2.32 \mathrm{ppm}$ and $47.72 \mathrm{ppm}$ in irrigated area while crop requirement nutrients are $20 \mathrm{ppm}$ and $200 \mathrm{ppm}$ respectively. And $\mathrm{Al}$ is in toxic level conditions, $27.5 \%$ in drained area while rice tolerance is $20 \%$. Fe was $641.51 \mathrm{ppm}$ in irrigated area while requirement narrowed to $300 \mathrm{ppm}$. As conclusion, the soil fertility is low and toxic which constitutes a limitation. The wetland soil in Rwanda should offer opportunities for paddy growing ( rice, etc), if soil fertility factors would be amended by lime for its acidity and gypsum for its exceeded $\mathrm{Na}$.
\end{abstract}

Keys words: : soil fertility; total nitrogen kjeldahl; wetland; gypsum; Rwanda.

\section{КАРТЫ РАЗДЕЛА «КЛИМАТ» ДЛЯ НОВОГО ИЗДАНИЯ ЭКОЛОГИЧЕСКОГО АТЛАСА РОССИИ}

\author{
Е. А. Божилина, В.Н. Сорокина, П.А. Торопов, К.А. Савельев \\ Географический факультет \\ Московский государственный университет имени М.В. Ломоносова \\ Москва, Россия \\ E-mail: bozilina@mail.ru
}

MAPS ALBUM «CLIMATE» FOR NEW EDITIONENVIRONMENTAL ATLAS RUSSIA

\author{
E.A. Bozhilina, V.N. Sorokina, P.A. Toropov, K.A. Saveliev \\ Faculty of Geography \\ M.V. Lomonosov Moscow State University \\ Moscow, Russia \\ E-mail: bozilina@mail.ru
}


Abstract. The content and the construction of legends map section «Climate» for the ecological Atlas of Russia: «climate Types», «Evaluation of discomfort climatic conditions», scale 1: 30000000 . Given a brief description of types of climate the territory of Russia. Approaches to the assessment of climate discomfort. Outlines the steps of creating a map discomfort of the climatic regions and given their description.

В настоящее время на географическом факультете МГУ готовится второе издание экологического атласа России [Касимов и др., 2011]. Это - фундаментальное научно-справочное комплексное собрание карт, отображающих экологическую обстановку в стране на рубеже нового тысячелетия.

Климат имеет особое значение для формирования экологической обстановки на территории России. Результаты мониторинга загрязнения атмосферного воздуха над территорией России целесообразно анализировать с учетом условий климатообразования, особенностей накопления и переноса примесей в атмосфере, влияния подстилающей поверхности и рельефа.

Данные любых точечных наблюдений за загрязнением должны быть увязаны с общими климатическими характеристиками. При анализе климатических характеристик и данных загрязнения для отдельных территорий России установлено, что неблагоприятные климатические условия могут приводить к двадцатикратному превышению обычного уровня загрязнения.

Накоплению вредных примесей в атмосфере часто способствуют условия барических образований с малыми градиентами изменения давления - антициклоны, седловины и размытые барические поля. Такие синоптические ситуации, как правило, сопровождаются образованием приземных инверсий температуры и слабых ветров, способствующих застою воздуха, что приводит к накоплению вредных примесей в атмосфере. Известно также, что туманы, которые аккумулируют примеси, также увеличивают степень загрязнения атмосферы. Солнечная радиация, обусловливающая фотохимические реакции в атмосфере, формирует в загрязненном воздухе фотохимический смог.

Рассеивание вредных примесей наблюдается при ультраполярных и северных вторжениях воздушных масс. Очищают атмосферу от аэрозолей и некоторых газообразных примесей интенсивные атмосферные осадки.

Авторы статьи провели экспериментальные работы и создали карты раздела «Климат» для экологического атласа России: «Типы климата», «Оценка дискомфортности климатических условий» в масштабе 1: 30000000.

\section{Характеристика типов климата.}

В качестве основного источника для создания карты типов климата использована карта климатического районирования из Национального атласа России масштаба 1: 15000 000, разработанная Е.А. Божилиной и В.Н. Сорокиной, справочники, монографии по климату России [Божилина и др., 2010; Мячкова, 1983; Национальный атлас России, 2007; Справочник, 1997].

Для карты разработана новая легенда, которая построена в виде матрицы. По вертикальной оси даются климатические пояса, по горизонтальной оси представлены типы климатов (см. рис.1). Внутри сетки табличной легенды размещаются таксоны климатических областей и их характеристики. Такое построение легенды позволило особо выделить типы климатов, которые имеют важное значение для формирования климатических условий, связанных с накоплением и переносом загрязняющих веществ. В процессе разработки карты нами произведена оценка типов климата. Приведем их краткие характеристики. Нами используется традиционное определение потенциала загрязнения атмосферы (ПЗА) как комплексной характеристики повторяемости неблагоприятных для рассеивания примеси в атмосфере метеорологических условий (температурных инверсий, застоев воздуха, слабых ветров, туманов) [Безуглая, 1983].

Tun 1. Океанических побережий. Наиболее благоприятные условия для переноса и рассеяния примесей в атмосфере складываются на арктическом европейском побережье, где из-за частого прохождения циклонов и берегового положения мала повторяемость слабых ветров (не более 20\%) и приземных инверсий - не более 20-30\% в году. Осадки часты и продолжительны. Туманы на этой территории формируются не более 40-60 дней в году. ПЗА на данной территории оценивается как низкий.

К востоку от Урала до устья Лены на побережье возрастает повторяемость антициклонов, особенно зимой, в связи с чем увеличивается повторяемость слабых ветров и приземных инверсий. Уменьшается количество и интенсивность осадков. ПЗА оценивается как умеренный. Арктическое побережье к востоку от устья Лены и тихоокеанское побережье характеризуются повышенным ПЗА, чему способствуют частые инверсии (до 45\%), особенно зимой, большая повторяемость слабых ветров - до 40\% в материковой части дальневосточных областей, особенно в бассейне Амура. Большие скорости ветра наблюдаются только на узкой полосе тихоокеанского побережья. Осадки на Дальнем Востоке выпадают в основном летом, а зимой, кроме Камчатки, они малы. Наиболее неблагоприятные условия для рассеивания примесей в атмосфере складываются зимой. Летом преобладает перенос на данную территорию океанических воздушных масс. Осадки часты, большой интенсивности, особенно в Амурской области. Летом из-за муссонной циркуляции отмечается некоторое увеличение адвективных приземных и приподнятых инверсий. В это время года при тумане и ослаблении скорости ветра можно ожидать повышение уровня загрязнения воздуха.

Tun 2. Умеренно-континентальный. В этом типе климата наибольшей циклоничностью, особенно летом, характеризуются северо-западные районы, где ПЗА оценивается как низкий. В юго-восточном направлении увеличивается повторяемость антициклональных образований, с чем связано увеличение 
повторяемости приземных инверсий и слабых ветров, наблюдается уменьшение в этом направлении в два раза числа дней с осадками.

В центральной и северо-восточной части европейской территории России ПЗА оценивается как умеренный. Здесь повторяемость приземных инверсий составляет 30-40\%. Число дней с туманом в основном не превышает за год 40. В разные периоды года создаются примерно одинаковые условия для накопления примесей в атмосфере.

На юге, а атлантико-континентальной степной области, повторяемость инверсий возрастает до 40-45 \%. Здесь возможно увеличение повторяемости низких приподнятых инверсий, особенно осенью, что способствует накоплению примесей в приземном слое атмосферы от низких источников. ПЗА оценивается как повышенный.

Tun 3. Континентальный. В этом типе климата степень загрязнения атмосферы в зависимости от физико-географических условий и циркуляции атмосферы изменяется в больших пределах. В континентально-европейской области, кроме побережья Каспийского моря, где велика повторяемость низких приземных инверсий, особенно зимой, и на западе континентально-сибирской области, где из-за влияния Уральских гор мала скорость ветра. ПЗА повышенный. На побережье Каспийского моря большая скорость ветра способствует снижению уровня загрязнения воздуха. Здесь выделяется узкая полоса умеренного ПЗА. Между долинами Оби и Енисея, где зимой отмечаются выходы черноморских циклонов, усиливающих скорость ветра, ПЗА понижается до умеренного.

Крайне неблагоприятные условия для рассеивания примесей в атмосфере складываются в континентальной области субарктического климата, где в холодный период года преобладает антициклональный режим атмосферной циркуляции и где в условиях пересеченного рельефа создаются благоприятные условия для формирования приземных инверсий и слабых ветров в приземном слое. Повторяемость инверсий в январе достигает наибольшей величины для территории России - 70-80\%. ПЗА в этой области изменяется с запада на восток от повышенного до высокого и очень высокого.

Tun 4. Резко-континентальный. В этом типе, где континентальность климата достигает предельной величины на Земле, складываются крайне неблагоприятные условия для рассеивания примесей в атмосфере и ПЗА оценивается как очень высокий. В холодный период года на этой территории преобладает антициклональный режим атмосферной циркуляции, в связи с чем в условиях пересеченного рельефа создаются благоприятные условия для формирования приземных инверсий и слабых ветров в приземном слое атмосферы. Повторяемость слабых ветров составляет 50-70 \% и более, а повторяемость инверсий в январе достигает наибольшей величины на территории России - 70-80\%. Зимой инверсии наблюдаются почти постоянно в течение суток. Условия застоя воздуха во всем пограничном слое определяют чрезвычайно низкую рассеивающую способность атмосферы и высокий ПЗА. Максимальная концентрация примесей в атмосфере наблюдается зимой.

Tun 5. Высокогорный. На Кавказе низкая рассеивающая способность атмосферы обусловлена преобладанием слабых ветров и мощных приземных инверсий. Повторяемость слабых ветров составляет 30 $60 \%$, но в зависимости от форм рельефа колеблется от $15-20 \%$ вблизи побережья Черного моря, до $65 \%$ в долинах. Повторяемость приземных инверсий составляет 40-50\%. Условия формирования приземных инверсий и застаивания воздуха имеют наибольшую повторяемость летом. Число дней с туманами изменяется существенно в зависимости от высоты и экспозиции. В высокогорной зоне они достигают 200 дней. Продолжительность и количество осадков изменяется в больших пределах. Максимум осадков отмечается весной и осенью, летом выпадает мало осадков. Максимальное загрязнение воздуха отмечается летом. ПЗА повышенный.

Большая часть горной системы Алтая и Саян характеризуется очень высоким ПЗА. Зимой эта территория находится очень близко к центру Азиатского антициклона. Повторяемость слабых ветров в зависимости от форм рельефа изменяется зимой от 40-50 \% у подножия склонов до 70-75\% в долинах и котловинах. Приземные инверсии в закрытых формах рельефа наблюдаются зимой в течение суток и повторяемость их составляет от 75 до 80\%. В 50-60\% случаев инверсии наблюдаются при слабом ветре. В котловинах осадков выпадает мало и в основном они выпадают летом. Максимум загрязнения воздуха наблюдается зимой. 




Рис. 1. Табличная часть легенды карты «Типы климата»

Оценка дискомфортности климата.

Важную роль в структуре раздела имеет также карта оценки дискомфортности климатических областей. Важнейшим показателем климатического потенциала региона является комфортность климата. От нее зависит плотность населения, а также перспективы экономического роста и тенденции обеспечения устойчивого развития территорий. В основу методики расчета большинства индексов комфортности положена зависимость интенсивности теплового излучения человеческого тела от трех важнейших метеорологических характеристик: температуры, скорости ветра и влажности. Также учитывается высота местности над уровнем моря. В зимнее время все перечисленные факторы увеличивают суровость климата. Например, средняя многолетняя температура января в посёлке Оймякон (северо-восток Якутии) составляет $46{ }^{\circ} \mathrm{C}$, а в посёлке Диксон (северо-запад Таймыра) $-30{ }^{\circ} \mathrm{C}$. Тем не менее, дискомфортность климата северовосточной Якутии характеризуется, как очень высокая, в то время, как климатические условия северозападного Таймыра определяются, как экстремальные. Так происходит из-за дополнительного охлаждающего воздействия ветра, который на побережья Арктики сильнее, чем в материковых районах, и повышенной влажности воздуха, которая, естественно, выше на морском побережье, нежели внутри континента. В регионах с теплым и жарким летом очень важно сочетание температуры и влажности воздуха - самые дискомфортные условия складываются в тех регионах, где высокая температура и влажность сочетается с низкими скоростями ветра.

В целом, две трети территории России (большая часть азиатской территории) отличаются погодным дискомфортом, который формируется, главным образом, за счет холодного периода. Отрицательные температуры наблюдаются здесь от 6 до 9 месяцев. В зимнее время погодные условия здесь меняются от индифферентных до крайне дискомфортных, а в отдельных случаях характеризуются, как экстремальные. В течение короткого периода положительных температур (3-6 месяцев) дискомфортность погодных условий, как правило, характеризуется, как умеренная, реже - как малая и очень малая. Исходя из этого, можно сделать вывод, что определяющую роль в формировании комфортности играет зимний период. Самым дискомфортным на территории России считается арктическое побережье страны от полуострова Ямал до мыса Дежнёва. Здесь средняя температура января колеблется от $-20^{\circ} \mathrm{C}$ до $-30^{\circ} \mathrm{C}$, в сочетании со средней многолетней скоростью ветра 5-10 м/с и повышенной влажностью. Поэтому условия характеризуются, как экстремальные. На втором месте - северо-восточные районы Якутии, континентальные районы Магаданской области и Чукотка. Здесь очень высокая степень дискомфортности: в материковых районах за счет экстремально низких температур воздуха $\left(-40 \ldots-45^{\circ} \mathrm{C}\right)$, а на берегах Берингова моря - за счет высокой 
влажности и высоких скоростей ветра (в сочетании со средней температурой января около $\left.-20{ }^{\circ} \mathrm{C}\right)$. Далее следует субарктический пояс на территории Красноярского края, Западной Сибири и Европейской территории страны. Здесь степень дискомфортности определяется, как высокая: к востоку от Урала за счет низких зимних температур (в среднем, -20..-30 ${ }^{\circ} \mathrm{C}$ ), на европейской территории - за счет большой повторяемости влажной и ветреной погоды. Степень комфортности несколько выше, чем в Арктике, за счет более теплого лета: средние суточные июльские значения температуры колеблются в пределах $10 \ldots 15{ }^{\circ} \mathrm{C}-$ это означает, что после полуденные значения составляют здесь $13 \ldots 18{ }^{\circ} \mathrm{C}$, нередко температура достигает и $+25^{\circ} \mathrm{C}$. Такие условия можно определить даже, как комфортные. В силу индифферентного, а отдельные годы даже комфортного лета, природные объекты субарктики довольно часто посещаются туристами и любителями активного отдыха.

Примечательно, что высокой степенью дискомфортности характеризуется не только субарктический пояс, но и большая часть Камчатки, побережье Магаданской области, Хабаровского края и даже Приморья. Происходит это за счет крайне неблагоприятных погодных условий зимой: сильные ветра, высокая влажность при отрицательной температуре воздуха. Например, Владивосток, расположенный на широте Сочи, характеризуется довольно высокой степенью дискомфортности. Это связано с особенностью атмосферной циркуляции в зимнее время: азиатский антициклон над материком и пониженный фон атмосферного давления над Тихим океаном обусловливают здесь северо-западные ветры, которые несут холодные воздушные массы из глубины материка. Средняя температура января здесь около $-10^{\circ} \mathrm{C}-э т о$ при высокой влажности и частой повторяемости сильных ветров. Не слишком комфортно здесь и летом: сочетание жары с высокой влажностью, неблагоприятное для большинства людей.

Средней степенью дискомфортности характеризуется Амурская область, Забайкалье, южные районы Восточной Сибири и большая часть Ханты-Мансийского округа. Летом в этих районах относительно комфортно. Но зимы довольно суровые, поэтому значения индекса дискомфортности не превышает 5.

Южные районы Сибири и Урала, а также большая часть Европейского севера (за исключением прибрежных районов) характеризуется уже умеренной степенью дискомфортности. Причина тому умеренно-суровые зимы и не жаркие летние сезоны, отсутствие высокой повторяемости штормовых и ураганных ветров. Конечно, в этих северных краях практически ежегодно наблюдаются периоды аномально морозной погоды зимой, а также сырой и прохладной погоды летом, что повышает дискомфортность климата. В летние месяцы причиной дискомфортности может быть и жара. Однако, в целом периоды дискомфортной погоды здесь невелики.

Северно-западные области, Средняя полоса, Черноземье, Средняя Волга и большая часть Европейского юга характеризуется малой степенью дискомфортности. Однако, следует отметить чрезвычайную изменчивость погодных условий в этих краях во все сезоны года. В итоге, индекс дискомфортности может меняться здесь от 2 до 11. Примечательно, что Нижняя Волга и Ставропольский край характеризуется более высокой степенью дискомфотности в летние месяцы - за счет высокой повторяемости высоких значений температуры $\left(32 \ldots 37^{\circ} \mathrm{C}\right)$.

Отсутствие дискомфортности на Черноморском побережье Кавказа также весьма условно. В летние месяцы здесь иногда наблюдаются периоды аномально теплой и влажной погоды, что понижает значения индекса. В зимнее время практически ежегодно случаются мощные вторжения холодного воздуха, которые на участке побережья Анапа-Туапсе становятся причиной штормовых и ураганных ветров - боры. В отдельные дни значения индекса могут понижаться до 2.

В исследованиях, проводимых в России, в основном, используются индексы, подробно описанные А.А. Исаевым [Исаев, 2003]. Для составления карты дискомфортности климата, были привлечены расчеты индексов суровости климата.

Среди индексов, относящихся к рассматриваемой категории, прежде всего, следует привести индекс жесткости погоды Бодмана (S):

$$
S=(1-0,04 \mathrm{~T})(1+0,272 \mathrm{~V}),
$$

где T - среднесуточная температура воздуха, V - среднесуточная скорость ветра в мlс.

В формуле Бодмана не учитывается абсолютная высота местности над уровнем моря $\left(\mathrm{H}_{\mathrm{m}}\right)$, сезонная изменчивость относительной влажности $\left(\mathrm{K}_{\mathrm{f}}\right)$,суточных амплитуд температуры воздуха $\left(\mathrm{A}_{\mathrm{t}}\right)$ и скорости ветра $\left(\mathrm{A}_{\mathrm{V}}\right)$. Учитывая данные факторы, В.И. Осокин ввел уточняющие коэффициенты в индекс Бодмана и получил следующее соотношение:

$$
S^{*}=(1-0,06 \mathrm{~T})(1+0,2 \mathrm{~V})\left(1+0,0006 H_{M}\right) K_{f} A_{t, V}
$$

Суровость зимы оценивается им баллами «суровости».

В ряде исследований используется индекс приведенной температуры, предложенный К.Ш.Хайруллиным и В.Н.Адаменко, в котором учитывается, помимо эффекта ветра, радиационный баланс поверхности тела, смягчающий холодовой дискомфорт при достижении определенной величины обогрева лица и рук человека.

Кроме того, для оценки суровости климата северных и горных территорий применяется биоклиматический индекс суровости метеорежима В.Ш. Белкина в основе которого лежит ряд эмпирических 
формул. Этот индекс позволяет учитывать влияние на организм человека не только низких температур, но и жарких условий полупустынных и пустынных районов, а также избыток ультрафиолета в горах и его дефицит в арктических широтах. Чем меньше индекс, тем больше дискомфортность климата. Используются и другие индексы для количественной оценки дискомфортности климатических условий.

Климат во многом определяет степень комфортности проживания человека на различных территориях. Климатические области России различаются по степени дискомфортности, которая зависит прежде всего от климатических характеристик холодного периода. Климат теплого периода на территории России в целом достаточно комфортен. Исключение составляют: Прикаспийская низменность, где летом относительно дискомфортная, сухая, очень жаркая погода имеет большую повторяемость, а также азиатское побережье Северного Ледовитого океана, где летом ветрено и влажная, прохладная погода.

\section{Этапы создания карты дискомфортности климатических областей.}

Создание карты проводилось в несколько этапов. На первом этапе был выполнен анализ карт климатического атласа СССР и раздела «Климат» Национального атласа России (2 том). Для анализа привлекались карты, характеризующие прежде всего дискомфортность климатических условий холодного периода: «Температура воздуха ниже $-30^{\circ} \mathrm{C}$, «Температура воздуха ниже $0^{\circ} \mathrm{C}$, «Минимальная температура воздуха», «Температура воздуха» (январь), «Абсолютный минимум температуры воздуха».

Дополнительно привлекались карты: «Температура воздуха выше $20^{\circ} \mathrm{C»,} \mathrm{«Продолжительность}$ солнечного сияния», «Ветровой режим» (средняя годовая скорость ветра м/с), «Относительная влажность воздуха» (январь, июль), «Атмосферные осадки» (год), «Метели», «Грозы», Абсолютный максимум температуры воздуха», «Число дней в году со среднесуточной температурой выше $0^{\circ} \mathrm{C»} \mathrm{и} \mathrm{справочники} \mathrm{[9].}$ Было выполнено районирование по распределению показателей, построенных на основе приведенных выше карт, и составлены рабочие схемы районирования. Эти схемы наносились на единую основу и изучались взаимосвязи. Было установлено, что распределение показателей на ЕТР примерно соответствует границам климатических областей на составленной нами карте «Типы климатов и климатические области». Для остальной территории границы были построены вновь с учетом рабочих схем. В результате была получена карта границ областей дискомфотности климата. Кроме того, для сравнительного анализа привлекалась карта «Районирование территории севера России по природно-климатическому фактору» в масштабе 1:45 000000 из НАР (том 3, 2008 г). Далее экспертами Е.А. Божилиной и В.Н. Сорокиной каждой их областей была присвоена степень дискомфортности, которая отражена в легенде карты (рис.2).

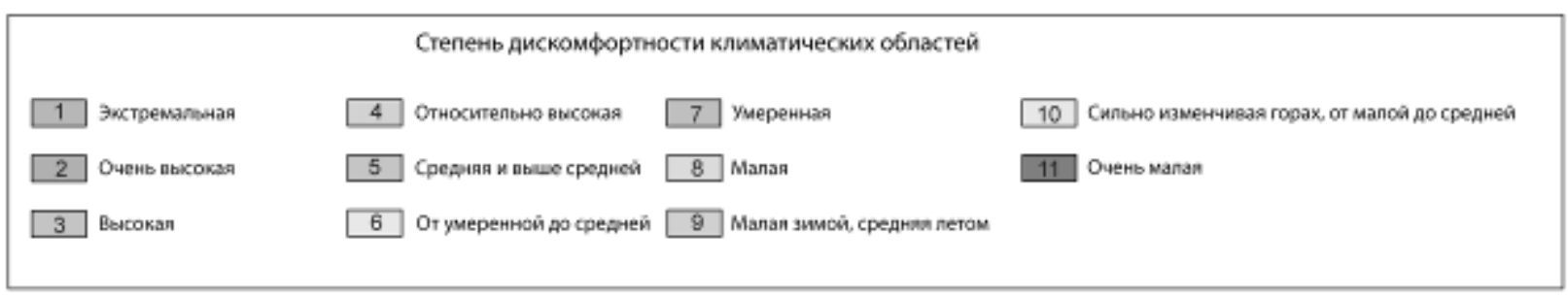

Рис. 2. Фрагмент легенды карты дискомфортности климатических областей.

Наибольший вес при выделении степени дискомфортности зимних климатических условий был отдан сочетанию низких температур с высокими скоростями ветра и значительной относительной влажностью воздуха. Так, например, район побережья арктических морей в Сибири отличается сочетанием низких температур (минимальная температура от -40 до -50С, число дней с температурой ниже -30 около 100) с высокой относительной влажностью воздуха и среднегодовой скоростью ветра 6-7 м/с. Ему присвоена эстремальная степень дискомфортности. Центральноякутский район при сходной повторяемости температур ниже $30 \mathrm{C}$ (около 100 дней), но низкой относительной влажности и небольшой скорости ветра (2 м/с), отнесен к категории относительно высокой дискомфорности.

Степень дискомфортности климатических областей дана на карте качественным цветовым фоном. Использовался ассоциативный принцип подбора цветов. Проводились эксперименты по оформлению, и был выбран оптимальный.

На втором этапе проводилась оценка степени суровости климата по пунктам. Расчёт степени суровости был выполнен доцентом кафедры метеорологии и климатологии П.А. Тороповым. Степень суровости климата по пунктам дана на карте в виде локализованных диаграмм.

Планируется продолжение работ над картами раздела. Особо пристальное внимание будет уделено созданию карт изменения температурного режима как проявлению глобального потепления XXI века. Проблема потепления климата, анализ и прогноз изменений температурного режима на территории России изучается специалистами в области климатологии [Груза, Ранькова, 2012; Кислов и др. 2008; Семенов, 1012; Торопов, Терентьев, 2011]. Однако отображение изменений температурного режима на картах часто дается без учета климатической «нормы», принятой для современного климата за разные временные интервалы Божилина, Суворов 2011]. Нами предлагается выполнить анализ изменений температурного режима для 
территории России за период принятый для современного климата (1961-1990 годы) и последнее десятилетие.

Литература.

1. Безуглая Э. Ю. Климатические характеристики условий распространения примесей в атмосфере: справочное пособие. Л.: Гидрометеоиздат, 1983. 328 с.

2. Божилина Е.А., А.К. Суворов А.К. Выбор временных интервалов и комплексирование баз данных для создания климатических карт // Сб. «ИнтерКарто/ ИнтерГИС 17: Устойчивое развитие территорий: Теория ГИС и практический опыт. Материалы международной конференции, Белокуриха (Алтайский край), Бали, Барнаул, 2011. С. 84-89.

3. Божилина Е.А., Емельянова Л.Г., Котова Т.В., Тальская Н.Н., Тутубалина О.В., Украинцева Н.Г. Географическое картографирование: карты природы: учебное пособие. - М.: КДУ, 2010.-316 с.

4. Груза Г.В. Ранькова Э. Я. Наблюдаемые и ожидаемые изменения климата России: температура воздуха. Обнинск: ФГБУ «ВНИИГМИ-МЦД», 2012. - 194 с.

5. Исаев А.А. Экологическая климатология. М.: Научный Мир, 2003. 472 с.

6. К Касимов Н.С, Котова Т.В., Тикунов В. С. Экологический атлас России: новый проект// Сб. «ИнтерКарто/ ИнтерГИС 17: Устойчивое развитие территорий: Теория ГИС и практический опыт. Материалы международной конференции, Белокуриха (Алтайский край), Бали, Барнаул, 2011. С. $277-282$.

7. Кислов А.В., Евстигнеев В.М., Малхазова С.М., Соколихина Н.Н., Суркова В., Торопов П.А., Чернышев А.В., Чумаченко А.Н. Прогноз климатической ресурсообеспеченности Восточно-Европейской равнины в условиях потепления XXI века. М.: Макс-Пресс, 2008. - 292 с.

8. Методы оценки последствий изменения климата для физических и биологических систем/ под ред. С.М. Семенова. М.: Росгидромет, 2012. . - 511 с.

9. Мячкова Н.А. Климат СССР. М.: Изд-во МГУ, 1983. 192 с.

10. Национальный атлас России. Т.2. М.: Роскартография, 2007. с. 146-150.

11. Справочник по опасным природным явлениям в республиках, краях и областях Российской федерации. С.-Пб.: Гидрометеоиздат, 1997. 587с.

12. Торопов П.А., Терентьев Б.А. Гидрометеорологический мониторинг в экосистемах АлтаеСаянского региона. Методическое пособие. М.:Изд-во WWF России, 2011. 132 с.

\title{
ИСТОРИЯ АТЛАСНОГО КАРТОГРАФИРОВАНИЯ СМОЛЕНЩИНЫ ${ }^{20}$
}

\author{
Т.В. Ватлина, С.П. Евдокимов \\ Смоленский государственный университет \\ г. Смоленск, Россия, ул. Пржевальского, 4. еsppaleogeо@таil.ru
}

HISTORY OF ATLAS MAPPING IN SMOLENSK REGION

\author{
T. Vatlina, S. Evdokimov \\ Smolensk State University \\ Smolensk, Russia, \\ e-mail:vatlina_geo@mail.ru \\ esppaleogeo@mail.ru
}

\begin{abstract}
History of atlas mapping in Smolensk region is described in the article from XVIII century to contemporary situation. Also the evolution of administrative territorial division of the territory in modern borders of Smolensk region is shown.

Как часть Московии Смоленщина отображена на многих картах XVII-XVIII веков. Однако первым картографическим произведением, посвященным именно этому краю, скорее всего, является «Атлас Смоленской губернии». Он состоит из 25 листов размером 25 на 20 см. Тираж неизвестен. Первый лист обзорная карта (рис. 1), 12 листов атласа представляют карты уездов Смоленской губернии, остальные 12 -
\end{abstract}

\footnotetext{
${ }^{20}$ Исследование выполнено при финансовой поддержке РФФИ в рамках научного проекта № 14-05-31109
} 